\title{
Concept of defensive medicine and litigation among Sudanese doctors working in obstetrics and gynecology
}

\author{
AbdelAziem A. Ali ${ }^{1 *}$, Moawia E. Hummeida ${ }^{2}$, Yasir A. M. Elhassan ${ }^{3}$, Wisal O. M.Nabag ${ }^{4}$, \\ Mohammed Ahmed A. Ahmed ${ }^{5}$ and Gamal K. Adam ${ }^{5}$
}

\begin{abstract}
Background: Obstetrics and gynaecology always has reputation for being a highly litigious. The field of obstetrics and gynaecology is surrounded by different circumstances that stimulate the doctors to practice defensive medicine.

Methods: This study was directed to assess the extent and the possible effect of defensive medicine phenomenon (in term of knowledge and prevalence) on medical decision making among different grades of obstetric and gynaecologic Sudanese doctors, and to determine any experience of medical litigations with respect to sources and factors associated with it (in term of area of work, characteristics of the area at which the doctors worked, professionalism, hospitals systems...ect).
\end{abstract}

Results: A total of 117 doctors were approached, their distribution according to job description was as follow: consultants $(42.7 \%, 50 \backslash 117)$ registrars $(34.2 \%, 40 \backslash 117)$ and specialists $(23.1 \%, 27117)$. The majority $89.7 \%$ had the impression that litigation against doctors are increasing and $27.6 \%$ had a direct experience of litigation. In this study less than one half (42.7\%) of the surveyed doctors knew the concept of defensive medicine and $71.8 \%$ reported practicing one or another form of defensive medicine. The different sources of the litigations reported by the doctors included: maternal death $(n=15)$, perinatal death $(n=5)$, other \{misdiagnosis, intra-uterine fetal death, uterine perforation, rupture uterus\} $(n=4)$, fetal distress $(n=3)$, injury to viscera $(n=3)$ and shoulder dystocia $(n=2)$. In this study the experience of medical litigation was significantly observed among those who worked in area of blame culture $(90.6 \%$ Vs $56.5 \%, P=0.000)$. In logistic regression model, there was no significant difference between those who knew the concept of defence medicine and those who didn't.

Conclusion: There should be strategic plan to reduce the practice of defensive medicine and medical litigation against doctors.

Keywords: Defensive, Litigation, Medicine, Obstetrics, Gynaecology, Sudan

\section{Background}

Defensive medicine is defined as a doctor's deviation from the usual practice in order to reduce or prevent criticism and $\backslash$ or complaints by patients or their relatives $[1,2]$. Some would claim that it is a legitimate phenomenon, while others consider it immoral [3]. In addition to this definition the United States Congress

\footnotetext{
* Correspondence: abuzianab73@yahoo.com

${ }^{1}$ Department of Obstetrics and Gynecology, Faculty of Medicine, Kassala

University, P.O. Box 496, Kassala, Sudan

Full list of author information is available at the end of the article
}

also include the action of ordering tests, procedures and visits, or avoidance of high risk patients or procedures with the primary (but not sole) aim of reducing mal-practice liability as a part of defensive medicine [4]. A genuine difficulty exists when trying to identify and quantify the extent of defensive medicine practices. This is partially because there is a grey area between proper and overly self-protective treatment. It may be difficult to recognize medical actions that are more likely to result in legal action. Obstetricians and Gynaecologists like other health 
care professional have a legal obligation to adhere to reasonable standards of care while acting in their professional capacity, they always has reputation for being a highly litigious [5]. Their field is surrounded by different circumstances that stimulate them to practice defensive medicine. About 5-7.4 \% of physicians in USA faced a malpractice claim annually [6]. Gynaecology alone had the 12th highest average annual proportion of physicians with a claim, with the highest payment rate (38 \%) [6]. Obstetrics and general surgery are regarded as high risk specialties [7]. As a result, the rising cost of malpractice insurance in obstetrics and genecology has led to a reality where doctors may refrain from treating high risk patients [7]. Again medical litigation represents a real threat for the doctors and may be a direct cause to leave the profession. Medical law is the aspect of the law which governs the relationship between the healthcare provider and patient [8]. The medical practitioner is bound by certain laws depending on the circumstances of his practice. Law and ethics may overlap since obtaining patient permission is both legally required and the "right thing to do" [8]. The Sudan Medical Council (SMC) standing disciplinary committee investigates any complaint that come to its notice or violation to medical ethics. The SMC has the power to erase doctors from its register or withhold the license of medical, dental or pharmacy institution or facility. Many studies were done worldwide concerning the medical litigation especially against obstetrics and gynaecology however none was carried out in Sudan thus this study was directed to assess the concept of defensive medicine (in term of knowledge and prevalence) and to determine any experience of medical litigations and their sources among different grades of Sudanese doctors working in obstetrics and gynaecology.

\section{Methods}

\section{Hypothesis}

While we did not adopt a formal hypothesis for this study, our working hypothesis/assumption was that defensive medicine affects daily doctor's clinical judgement and practice.

\section{Study design and data collection}

This study was directed to assess the extent and the possible effect of defensive medicine phenomenon (in term of knowledge and prevalence) on medical decision making (development of tools that can guide physicians to make good decisions in practice) among different grades of obstetric and gynaecologic doctors, and to determine any experience of medical litigations with respect to sources and factors associated with it (in term of area of work, characteristics of the area at which the doctors worked, professionalism, hospitals systems...ect). Using a self administered questionnaire (Additional file 1) and after obtaining informed written consent the data was collected from the different certified OBGYN professionals (Registrars, Specialists and Consultants) working in obstetrics and gynaecology and who attended the 27th congress of obstetrical and gynaecological society of the Sudan held from (20th -23rd February 2015) in Khartoum. The survey included only Sudanese doctors who were practicing obstetrics and gynaecology in Sudan. Visiting Doctors who are practicing in a different context abroad were excluded from the study. We used a questionnaire which was constructed by the authors to consider different forms of defensive medicine and medical litigation in obstetrics and gynaecology. Information sought by the questionnaire included: sociodemographic characteristics (age, grade, gender, area of work, duration of work, health insurance coverage), information on the area of work (blame culture: which defined as no one accepts medical errors as being all right), information on the hospital where the respondent worked (hospital guidelines and protocol, auditing system, committees...ect) daily experience (informed consent, high risk consent, documentation), whether the respondents knew the concept of defensive medicine or not? and questions on different examples of positive and negative defensive medicine (prescription of unnecessary medication, experience unnecessary refer, refuse to manage high risk patient, request for unnecessary investigation, experience unnecessary surgical procedure and avoidance high risk surgical procedure because of fear of criticism or litigation). Other information obtained from the respondents included: is the litigation in OBGYN increasing?, whether the respondents experienced litigations during their daily practice and the source of the litigations (fetal distress, misdiagnosis, injury to the viscera, shoulder dystocia, death...ect). The definition of defensive medicine was framed by the investigators according the definition in the literature [1]; defined as a doctor's deviation from their usual behaviour or that considered good practice, to reduce or prevent complaints or criticism by patients or their families. This definition was not set out in the questionnaire for the respondents however in the questionnaire we asked the respondents whether they know the defensive medicine or not. Defensive medical practices were further subcategorized into positive and negative practice. When extra tests and procedures are performed primarily to reduce malpractice liability, this is a positive defensive medicine. Negative defensive medicine consists of avoidance of certain patients and procedures, thereby withdrawing medical services, and can deny patients productive care [2]. In the questionnaire we explained the situation of high risk consent which is taken in case of serious / complicated / risky / new - surgeries or procedures; for 
removing any organ; in high risk patients; for proceeding with a surgery / procedure in spite of any abnormal parameters of the patient. This list is indicative not exhaustive and in case of a dilemma it is always advisable to take this high-risk consent and not a general consent.)

\section{Statistics}

Data were entered into a computer database and SPSS software (SPSS Inc., Chicago, IL, USA, version 16.0) and double checked before analysis. Chi-squire test was used and $P<0.05$ was considered significant. Univariate and multivariate analyses were performed. Defensive medicine was the dependent variable and other variables were independent factors. Confidence intervals of $95 \%$ were calculated and $P<0.05$ was considered significant. In case of discrepancy between the results of univariate and multivariate analyses, the later was taken as final.

\section{Ethics}

The study received ethical clearance from the Health Research Board at Ministry of Health, Kassala State, and Sudan Medical Specialization Board (SMSB), Obstetrics and Gynaecology Department, Sudan.

\section{Results}

\section{Characteristics of the respondents and area of work}

A total of 117 doctors were approached, their age ranged from 26 to 73 years. Their distribution according to job description was as follow: consultants $(42.7 \%, 50 \backslash 117)$ registrars (34.2 \%, 40\117) and specialists (23.1\%, 27\117), Table 1. Of them 106 (90\%) worked in teaching hospital, 11 (9.4 \%) in rural hospitals, again 39 (33.3\%) of the respondents claimed that they worked in blame free culture while $78(66.7 \%)$ believed the opposite. More than half of the participants were female $60 \backslash 117$ $(51.3 \%)$ and the majority $(76 \backslash 117,65 \%)$ were not covered by health insurance. With regard to duration of experience in obstetrics and gynaecology $14.5 \%$ had an experience of less than 5 years, (41.9\%) were of 510 years and $43.6 \%$ were more than 10 years of experience. Again with respect to the area of work the vast majority of the investigated doctors mentioned that their hospitals having guidelines and protocol (58.1\%), auditing system (72.6 \%) however only $45.3 \%$ and $39.3 \%$ reported having high risk and ethical committees respectively. Respondents reports on daily experience and practices with regards to documentations/and communications was quite variable: they always (61.5\%), usually (29.1\%) and sometimes (9.4\%) applied informed consent, always (55.6\%) usually (25.6\%) and sometimes (18.8) applied high risk consent and they always $(39.7 \%)$, usually (43.6 \%) and sometimes (17.1\%) documented their findings and intervention.
Table 1 Characteristics of the respondents and the area of work $(n=117)$

\begin{tabular}{|c|c|c|}
\hline Variable & Frequency & Percentage \\
\hline \multicolumn{3}{|l|}{ Job description } \\
\hline Consultant & 50 & $42.7 \%$ \\
\hline Registrar & 40 & $34.2 \%$ \\
\hline Specialist & 27 & $23.1 \%$ \\
\hline \multicolumn{3}{|l|}{ Duration of work } \\
\hline$<5$ years & 17 & $14.5 \%$ \\
\hline $5-10$ years & 49 & $41.9 \%$ \\
\hline$\geq 10$ years & 51 & $43.6 \%$ \\
\hline \multicolumn{3}{|c|}{ Distribution per gender } \\
\hline Female & 60 & $51.3 \%$ \\
\hline Male & 57 & $48.7 \%$ \\
\hline \multicolumn{3}{|l|}{ Hospital } \\
\hline Teaching & 106 & $90 \%$ \\
\hline Rural & 11 & $10 \%$ \\
\hline \multicolumn{3}{|c|}{ Culture of the area of work } \\
\hline Blame area & 39 & $33.3 \%$ \\
\hline Blame free area & 78 & $66.7 \%$ \\
\hline \multicolumn{3}{|c|}{ Health insurance coverage for the respondents } \\
\hline Covered & 41 & $35 \%$ \\
\hline Not covered & 76 & $65 \%$ \\
\hline
\end{tabular}

\section{Medical litigation}

The majority $89.7 \%(n=105)$ had the impression that litigation against doctors are increasing and $27.6 \%(n=$ 32) had a direct experience of litigation. The different sources of the litigations reported by the doctors included: maternal death $(n=15)$, perinatal death $(n=5)$, other (misdiagnosis, intra-uterine fetal death, uterine perforation, rupture uterus $\}(n=4)$, fetal distress $(n=3)$, injury to viscera $(n=3)$ and shoulder dystocia $(n=2)$.

\section{Defensive medicine}

Less than one half $(50 \backslash 117,42.7 \%)$ of the surveyed doctors knew the concept of defensive medicine and $71.8 \%$ $(n=84)$ reported practicing one or another form of defensive medicine. With further classification of defensive medicine; 48 (41\%) reported practicing positive defensive medicine while 36 (30.8 \%) reported practicing negative one. Arranging un-necessary refer was the most common form of defensive medicine practiced by the investigated doctors $(n=27,23.1 \%)$ followed by avoiding high risk procedure $(n=24,20.5 \%)$ and ordering unnecessary investigations $(n=14,12 \%)$. Among our respondents 7 (6\%) prescribed un-necessary medication to avoid litigation and criticism, 6 (5.1\%) refused to manage high risk patient because of fear from litigation 
and $6(5.1 \%)$ performed un-necessary surgery (caesarean section) to avoid litigation and criticism.

\section{Factors associated with medical litigation and defensive medicine}

In this study the experience of medical litigation was significantly observed among those who worked in area of blame culture $(90.6 \%$ Vs $56.5 \%, P<0.001)$, Table 2 while in logistic regression model the different variables (duration of work, qualification, place of work and area of blame culture) were not associated with the concept of defence medicine, Table 3.

\section{Discussion}

To our knowledge this is the first published data on concept of defensive medicine and medical litigation among Sudanese doctors. The majority $89.7 \%$ had the impression that litigation against doctors are increasing and $27.6 \%$ had a direct experience of litigation. In this study less than one half $(42.7 \%)$ of the surveyed doctors knew the concept of defensive medicine and $71.8 \%$ reported practicing one or another form of defensive medicine. Worldwide there is a growing awareness of the need for more effective communication among caregivers, patients, and their families [9]. With the increasing rates of negligence, patients are beginning to seek redress and are being enlightened by legal practitioners. Health care

Table 2 Factors associated with medical litigation among Sudanese doctors working in obstetrics and gynaecology, 2015

\begin{tabular}{|c|c|c|c|}
\hline Variables & $\begin{array}{l}\text { Experienced litigation } \\
(N=32)\end{array}$ & $\begin{array}{l}\text { Didn't experience litigation } \\
(N=85)\end{array}$ & $P$ \\
\hline $\begin{array}{l}\text { Area of work, } \\
\text { teaching } \\
\text { hospital }\end{array}$ & $28(87.5)$ & 77 (90.6) & 0.357 \\
\hline $\begin{array}{l}\text { Hospital } \\
\text { protocol, yes }\end{array}$ & $16(56.2)$ & $50(58.8)$ & 0.454 \\
\hline $\begin{array}{l}\text { High risk } \\
\text { committee, } \\
\text { yes }\end{array}$ & $14(43.8)$ & 39 (45.9) & 0.481 \\
\hline $\begin{array}{l}\text { Hospital } \\
\text { auditing } \\
\text { system, yes }\end{array}$ & 21 (65.6) & $64(75.2)$ & 0.179 \\
\hline $\begin{array}{l}\text { Area of } \\
\text { blame } \\
\text { culture, yes }\end{array}$ & 29 (90.6) & $48(56.5)$ & 0.000 \\
\hline $\begin{array}{l}\text { Hospital } \\
\text { ethical } \\
\text { committee, } \\
\text { yes }\end{array}$ & 13 (40.6) & 33 (38.8) & 0.529 \\
\hline $\begin{array}{l}\text { Informed } \\
\text { consent, } \\
\text { always }\end{array}$ & 19 (59.4) & $53(62.3)$ & 0.917 \\
\hline $\begin{array}{l}\text { High risk } \\
\text { consent, } \\
\text { always }\end{array}$ & $13(40.6)$ & $51(60.0)$ & 0.067 \\
\hline
\end{tabular}

Data are shown as number (\%) as applicable
Table 3 Factors associated with concept of defence medicine among Sudanese doctors working in obstetrics and gynaecology, 2015, using univariate and multivariate analyses

\begin{tabular}{llllllll}
\hline Variable & \multicolumn{3}{l}{ Univariate analyses } & \multicolumn{4}{c}{ Multivariate analyses } \\
\hline & OR & $95 \% \mathrm{Cl}$ & $P$-value & OR & $95 \% \mathrm{Cl}$ & $P$-value \\
& 0.9 & $0.9-1.0$ & 0.017 & 0.9 & $0.9-1.0$ & 0.154 \\
$\begin{array}{l}\text { Duration of work } \\
\geq 5 \text { year }\end{array}$ & & & & & & \\
Qualification, consultant & 1.9 & $1.1-3.1$ & 0.009 & 1.6 & $0.9-2.8$ & 0.081 \\
Place of work, & 0.6 & $1.0-2.0$ & 0.409 & 0.4 & $1.0-1.6$ & 0.217 \\
teaching hospital & & & & & & \\
Area of blame culture & 1.3 & $0.5-2.8$ & 0.509 & 1.4 & $0.6-3.3$ & 0.372 \\
\hline
\end{tabular}

Abbreviations: $\mathrm{OR}$ odds ratio, $\mathrm{Cl}$ confidence interval

practitioners are thus confronted with the problem and risk of being sued. This is believed to have influence various aspects of gynecological and obstetrical practice [10]. Thus the National Heath Care system in Sudan should insures medical staff employees, providing compensation to victims of alleged malpractice, including reasonable court fees. This will allow the health practitioners to exercise their minds individually and jointly to effectively give better service to patients. Less than one half of the investigated doctors in this study practiced defensive medicine. Defensive medicine was reported in $96 \%$ among the USA neurosurgeons and in Europe $94 \%$ of the gastroenterologists reported practicing defensive medicine [11]. The practice of defensive medicine has also spread to Italy where $83 \%$ of the surgeons and anesthetists reported practicing defensive medicine $[12,13]$. In Japan $98 \%$ of the gastroenterologists also reported practicing at least one or another form of defensive medicine [14]. This discrepancy might be attributed to the culture of area and people motivation and awareness. In 1991 Ennis et al. investigated the members and fellows of the Royal College of Obstetricians and gynecologists and found that the majority of the surveyed doctors were using some of tests which were known to them as unnecessary [15]. The most frequent explanations given for this practice were that such tests were an aid to clinical judgment and were necessary for medicolegal reasons. However we don't believe this is an excellent explanation to practice defensive medicine. In the literature many studies suggested that there is significant association between medical litigation and specialty, however and inconsistent with Ortashi et al. our study did not show any significant different in the practice of defensive medicine among different specialties [2]. Also in line with Ortashi et al. our study revealed no significant correlation between litigation and different investigated variables. Defensive medicine brings with it exponential increases in the costs associated with clinical practice. This is explained by poor communication and other causes of medical litigation such as poor decision making. Doctors' decisions for their patients are strongly 
affected by concerns of possible legal consequences. Doctors therefore practice defensive medical decision making aiming to protect themselves from blame and litigation and some fears can be healthy and can lead to adaptive responses. Good process should help create trust, rapport and alliance by showing respect for the patient. Lack of ethical issues as well as hospitals guidelines will lead to increase in the medical litigation and thus defensive medicine; this is obviously observed among our respondents since only $45.3 \%$ and $39.3 \%$ reported having high risk and ethical committees respectively.

\section{Conclusion}

The majority of Sudanese doctors who are working in Obstetrics and Gynaecology had the impression that litigation against doctors are increasing, almost one third had a direct experience of litigation and more than two thirds reported practicing one or another form of defensive medicine. There should be strategic plan to reduce the practice of defensive medicine and medical litigation against doctors.

\section{Additional file}

\section{Additional file 1: Concept of Defensive Medicine and Litigation among} Sudanese Doctors Working in Obstetrics and Gynecology (DOCX 28 kb)

\section{Competing interests}

The authors declare that they have no competing interests.

\section{Authors' contributions}

EYAM, NWOM and AMAA carried out the study and participated in the statistical analysis and procedures. AAA, HME and AGK coordinated and participated in the study design, statistical analysis and the drafting of the manuscript. All the authors read and approved the final version.

\section{Acknowledgements}

We would like to thank all the doctors who participated in this study.

\section{Author details}

Department of Obstetrics and Gynecology, Faculty of Medicine, Kassala University, P.O. Box 496, Kassala, Sudan. ${ }^{2}$ School of Medicine, Alneelain University, Khartoum, Sudan. ${ }^{3}$ Faculty of Medicine, Kordofan University, ElObeid, Sudan. ${ }^{4}$ Faculty of Medicine, Alzaiem Alazhari University, Al-ShaBiyya, Sudan. ${ }^{5}$ Faculty of Medicine, Gadarif University, AlGadarif, Sudan.

Received: 16 August 2015 Accepted: 2 February 2016

Published online: 09 February 2016

\section{References}

1. Toker A, Shvarts S, Perry ZH, Doron Y, Reuveni H. Clinical guidelines, defensive medicine, and the physician between the two. Am J Otolaryngol. 2004;25(4):245-50

2. Ortashi O, Virdee J, Hassan R, Mutrynowski T, Abu-Zidan F. The practice of defensive medicine among hospital doctors in the United Kingdom. BMC Med Ethics. 2013;14:42

3. Kessler DP, McClellan M. Do doctors practice defensive medicine? Q J Econ. 1996:111:353-90

4. Corrigan J, Wagner J, Wolfe L, Klingman D, Polishuk P. Report from congress medical malpractice reform 4 and defensive medicine. Cancer Invest. 1996; 14(3):277-84.
5. Studdert DM, Mello MM, Sage WM, DesRoches CM, Peugh J, Zapert K, et al. Defensive medicine among high-risk specialist physicians in a volatile malpractice environment. JAMA. 2005;293:2609-17.

6. Jena $A B$, Seabury $S$, Lakdawalla $D$, Chandra A. Malpractice risk according to physician specialty. N Engl J Med. 2011;365:629-36.

7. Zwecker P, Azoulay L, Abenhaim HA. Effect of fear of litigation on obstetric care: a nationwide analysis on obstetric practice. Am J Perinatol. 2011;28(4):277-84.

8. Chawla A, Gunderman RB. Defensive medicine: prevalence, implications, and recommendations. Acad Radiol. 2007:15(7):948-9.

9. Eastaugh SR. Reducing litigation costs through better patient communication. Physician Exec. 2004;30:36-8.

10. Schifrin BS, Cohen WR. The effect of malpractice claims on the use of cesarean section. Best Pract Res Clin Obstet Gynaecol. 2013;27(2):269-83.

11. Sethi MK, Obremskey WT, Natividad H, Mir HR, Jahangir AA. Incidence and costs of defensive medicine among orthopedic surgeons in the United States: a national survey study. Am J Orthop (Belle Mead NJ). 2012;41(2):69-73.

12. Elli L, Tenca A, Soncini M, Spinzi G, Buscarini E, Conte D. Defensive medicine practices among gastroenterologists in Lombardy: between lawsuits and the economic crisis. Dig Liver Dis. 2013;45(6):469-73. doi:10.1016/j.dld.2013.01.004.

13. Catino M, Celotti S. The problem of defensive medicine: two Italian surveys. Stud Health Technol Inform. 2009;148:206-21.

14. Hiyama T, Yoshihara M, Tanaka S, Urabe $Y$, Ikegami $Y$, Fukuhara $T$, et al. Defensive medicine practices among gastroenterologists in Japan. World J Gastroenterol. 2006;12(47):7671-5.

15. Ennis M, Clark A, Grudzinskas JG. Change in obstetric practice in response to fear of litigation in the British Isles. Lancet. 1991;338(8767):616-8.
Submit your next manuscript to BioMed Central and we will help you at every step:

- We accept pre-submission inquiries

- Our selector tool helps you to find the most relevant journal

- We provide round the clock customer support

- Convenient online submission

- Thorough peer review

- Inclusion in PubMed and all major indexing services

- Maximum visibility for your research

Submit your manuscript at www.biomedcentral.com/submit
C BioMed Central 